\title{
The Reflections of Enterprise Management Decisions in the Big Data
}

\section{Background}

\author{
Zewei Li \\ Macau University of Science and Technology, 000853 \\ 346591653@163.com
}

Key words: big data; enterprise management; decisions

\begin{abstract}
With the widespread use of ICT, particularly the expansionary development of cloud computing and processing technology, the human society entered into the information age of data processing supported by large data. Based on rich experience from many years' work, the author, first of all, analyzes enterprise management decisions system supported by big data, and, in the background of big data, discusses the plight of enterprise management decisions, and finally puts forward the countermeasures to enterprise management decisions. For enterprises, enterprise management decisions, in the era of big data, is a new model, which may bring about changes in the business model.
\end{abstract}

\section{Enterprise Management Decisions System Supported by Big Data}

In the background of the big data, massive and complex data challenges the original technology construction of enterprise management decisions system, and it also has a higher requirement on the capacity of data analysis and data-driven business. In order to make better use of the technologies related to the big data and apply them to the enterprise management decisions, a new model of enterprise management decisions system supported by the big data needs to be built to optimize and reorganize the original enterprise business process and integrate various types of data.

Enterprise management decisions system supported by the big data can be divided into three levels, namely: data obtaining, data processing and data application. There are four main sources of data acquisition: accession data; transaction data; network data and purchase data. Data processing level, also known as decision coordinated control system, is divided into five subsystems, namely: acquisition subsystem of decision-making data, analysis subsystem of decision-making data, filtering subsystem of decision-making data, services subsystem of decision-making data, and coordination and control subsystem of decision-making data, whose function is separately data collection, analysis, screening, service, coordination and control. Application level is the business strategy based on the big data, including: production strategy, marketing strategy, financial strategy, operating strategy, customer service strategy and public relations strategy.

The model in Fig. 1 demonstrates that using big data technology, enterprises aim to enhance the scientific decision-making management, whose essence is a new business strategy decision system of the combination of human-computer in the new situation. Through the functions of collection, analysis, filtering, servicing, coordination and control of the internal decision-making system, enterprisers can judge the developmental trend of their enterprises as well as the whole business. They can also track non-continuous changes of market and customers, analyze their own capabilities and trends as well as their competitors and integrate decisions resource by making full 
use of the big data. By making and applying scientific decision-making systems or methods, entrepreneurs make a more scientific business decisions to ensure the coordinated operation of various departments, forming a dynamic and orderly mechanism for cooperation and combining decision-making system of enterprises with their external environment, which helps enterprises to make scientific and rational business decisions that ensure their business competitive advantage in the market.

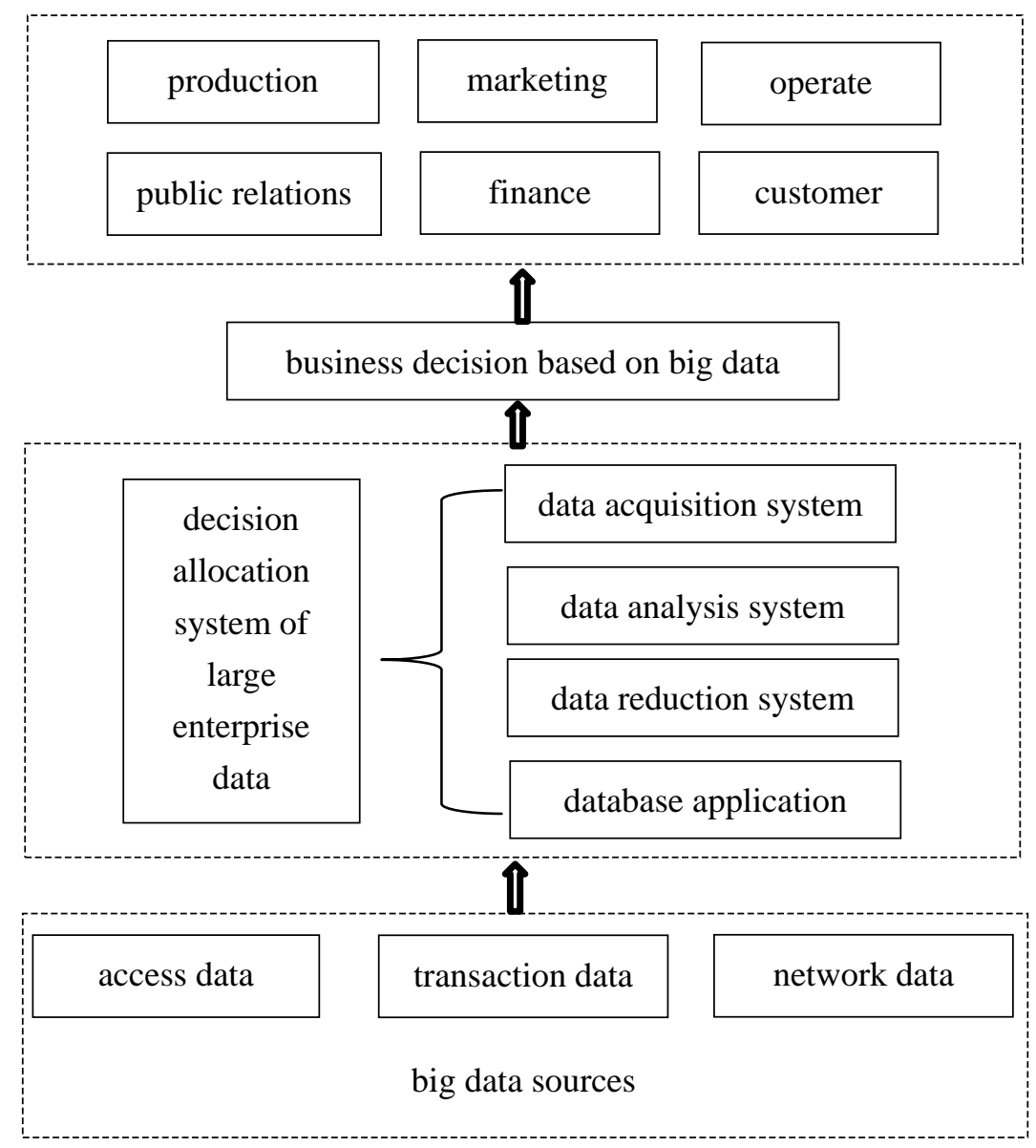

Fig.1 enterprise management decision making system based on big data

\section{The Plight of Enterprise Management Decisions in the Background of Big Data}

The more complicated environment. The big data based on cloud computing, on one hand, provides a wider space in the enterprise decision-making process. On the other hand, the decision-making environment enterprises faced with are changing more and more rapidly, and a variety of business-related data, particularly those resulting from accidental events, constantly generate, spread and reserve, which objectively requires enterprises to integrate data as soon as possible through the platform of cloud computing to build a highly integrated enterprise management decisions system by which enterprises can fully tap, collect, analyze and store data to form vast amounts of enterprise data assets. Therefore, in the background of the big data environment, complicated environmental factors affect the collection and analysis of information in enterprises' decision-making, formation and selection of decision-making program, thus affecting enterprises' unified management of data, which subjectively increases the difficulty for the decision makers to manage. 
era of the big data, data on the Internet explosively increases, and the amount of data in human society generated each year has jumped from TB level to PB, EB, and even ZB level. The information contained in the data has gone beyond the scope of data processing capacity of general enterprise managers, which not only increases the workload of processing information for it is difficult to use the traditional techniques of data management and analysis to effectively tap the potential value of these data, but also leads to more difficulty to analyze the value of the information, which makes it more hard to judge, select and use the information value when enterprises make decisions management. Only by establishing new, powerful business management decisions system based on the big data technology, it may be better for enterprises to acquire, screen, classify and select valuable data, which helps enterprises to make more scientific decisions.

Decision-making process of enterprises lagging behind the market changes. Traditional decision-making process of enterprises generally goes through a long period for data collection, research, analysis and appraisal, selection and evaluation program. But the complexity of the decision-making process is likely to lead to decision-making hysteresis, because of which, enterprises may eventually miss development opportunities. In the era of the big data, it is more urgent to make the decision-making process highly simplified for enterprises to make scientific decisions. The fierce competition of the market requires enterprises to take actions before others and make decisions fast in order to seize the commanding heights of the market. The competition of enterprises in the future is mainly based on that of the big data. Through applying data mining and functions of classification and integrity in the big data, entrepreneurs find out valuable data for enterprises to refer to and they make quickly judgment and option, make a choice, optimize the scheme and make decisions.

The more diversified main bodies in decision-making of enterprises. In the informational industry age, as the need of technology and knowledge-based decision-making of enterprises continue to increase while the data is constantly growing, many experts and scholars, and even technical staffs also join in the decision-making group. The main bodies in decision-making of enterprises increase. And because of the diversified members and multifaceted knowledge of the members of the think tank in decision-making, which, to a certain extent, can decrease the error rate of the collective subjective judgment in enterprise decision-making. Correspondingly, in order to improve the scientific level of decision management, enterprise-wide decision management system should be established as soon as possible, technologies of data collection, analysis, screening in the big data should be applied widely, forming a scientific decision-making data indicators, which can serve the management decisions better.

The traditional method of enterprise decision-making to be innovative. In the era of the big data, enterprises' making decisions must be based on the data. The study of the big data research differs from traditional logic reasoning. It is to do classification and induction such as statistical search comparison, clustering, classification on a great number of data, paying attention on Relevance or association of the data. By building enterprise management decisions system supported by big data, entrepreneurs seek to find out some hidden regularity and mutual relationships in a large number of data, usually reflected by parameters of support, credibility, interest. It is possible to provide strategic support for enterprise management decisions by just finding some way from data mining which has a strong correlation with the increase of corporate profits. The correlation of the data and its importance on decision-making of enterprises 
subjectively require managers adapt to the situation and improve the management approach.

\section{Strategies of Enterprise Decision Management in the Background of Big Data}

Adapting to environmental changes in order to build enterprise-class big data integration system. In order to solve the difficulty of the decision-making increased due to the growing variables, making it possible to efficiently analyze the information and make judgment when using the cloud computing model and Big Data technology to response to rapidly changes of the business environment enterprises are facing, enterprises should rebuild informational enterprises on the base of enterprises decision management system supported by the big data, and different levels of enterprises should build and apply suitable data integration systems, reflecting its practical, comprehensive and extensive features. Through the big data integration system, enterprises can obtain business-related data sources smoothly to understand users' behavior and feedback, focus on tracking and collecting users' behavior and pay equal attention to these features in product design and project planning, which is helpful for products to be more closer to the market, to meet the needs of consumers.

Using data mining technology to analyze and deal with information related to business decision-making process. After getting a lot of the original source data, enterprises can find out noise-containing data, error data and the redundant data through data cleaning technologies and preliminary identify and screen the data, using data integration technology to unite data from multiple data resources and put them into a consistent data storage warehouse. At the same time, enterprises can use linear or non-linear mathematical transformation method to compress cube into smaller dimension data and eliminate the differences in space, property, time and accuracy, making the presented search results more valuable and practical for enterprise decision-making.

Establishing internal decision-making system and optimizing decision-making process. In the era of the big data, enterprise managers should establish modern information communication platform where they can make targeted and purposeful communication with employees and even make decisions. When adjusting major policies and facing major events, enterprises, through information communication platform, optimize information channels and routing of communication to make decision-making procedures simple and fast, to encourage participants of the decision-making process to join in the communication fast, put forward reasonable suggestions and participate in decision-making programs, which can shorten the communication time between managers and employees. The length of the information chain should be shortened, the optimization and integration efforts of the information chain should be strengthened in order to optimize business operations processes, reduce the degree of deviation of internal communication, thereby reducing the complexity of making management decision. A virtual network platform can improve and enhance enterprise decision management, so that the operation is standardized, management scientific, development more efficient and competitiveness comprehensive.

Broadening the main body of decision-making in order to reduce the risk of decision-making. With the constant evolution of the market, new business, new products continue to emerge, expanding the scope of enterprises' decisions, and main bodies who make decisions are becoming increasingly complex. Especially with the economic globalization and informational development, the decision-making environment is changing rapidly. If enterprises are still relying solely on very few groups or decision-making bodies, just like they do in the past, to make decisions, it will be 
obviously difficult for them to ensure the scientific quality and predictability of decision-making. In the era of big data, enterprises should pay attention to the role played by intelligence agencies, relevant professional advisory bodies and think tanks, getting them involved in the scope of the decision-making body to form a multi-level decision-making body system in order to reduce the risk of decision-making and guarantee the specialization.

Improving traditional decision-making methods and applying advanced decision-making thought. When collecting and processing the big data, enterprises manage, filter and transform different massive data sources. They analyze the results with techniques of visualization, making it possible for enterprises intelligence to acquire and apply. They should abandon the research thought that when making decisions, enterprises should think firstly about the data and then information before making decisions" but take the shortcut of "discovering the value from the data and applying it directly to the decision-making”. As long as the method of the data analysis is helpful to major business decisions of enterprises, variable definition, uncertainty and value modeling by the big data can be carried out to analyze the quantitative risk of the enterprise decision management, making the decision-making more scientific.

\section{Conclusion}

Big data provides a new environment and cutting-edge perspective for the enterprise decision management, which has a profound impact and promote its continuous innovation and change. Enterprise needs to obtain core competitiveness in the era of big data. To meet its need, enterprise decision management will take the road of combining traditional decision-making methods with big data technique. Only by enhancing data analysis and application capabilities in big data environments by big data technique can enterprises increase the efficiency and capacity of enterprise decision management.

\section{References}

[1]Zheng Li. An Analysis of Informational Management of Enterprise Archives under the big data background[J]. Lantai World,2014,S4:113-114.

[2]Xu Wenfei. An Analysis of the Effect the Big Data Has on Firm Management and Decision[J]. Theory of China,2015,10:38-40.

[3]Tang Guliang, Zhang Shouwen. Challenges and Change of Financial Management under the Background of Big Data[J]. Fiscal Studies,2015,01:59-64.

[4]Li Zhongshun, Zhou Liyun, Xie Weihong, Cheng Minghui, Dong Yanfeng, Jiang Luan. A Study on the Effect the Big Data Has on the Enterprise Management Decisions[J]. Science and Technology Management Research,2015,14:160-166.

[5]Zhang Dai. An Analysis of Strategies of Enterprise Financial Management under the Background of Big Data[J]. Modern Economic Information,2015,21:172-173. 